\title{
O CONCEITO DE ANTAGONISMO NA FILOSOFIA POLÍTICA DE KANT ${ }^{1}$
}

\author{
José Gomes André2
}

\begin{abstract}
RESUMO: Embora ocupe um lugar importante na arquitectura conceptual do pensamento kantiano, a noção de antagonismo raramente merece especial atenção dos estudiosos de Kant. Este artigo procura combater esse esquecimento, enfatizando a relevância daquele conceito, em particular na filosofia política de Kant. Serão consideradas nomeadamente a dualidade/convergência dos conceitos de "guerra" e "paz" e a forma como a noçấo de antagonismo serve de sólido alicerce para a ideia kantiana de progresso. Procurarei mostrar como a proposta de edificação de um estado de direito (em um nível interno e externo) é, no fim de contas, gerada por um estímulo negativo - a discórdia intersubjectiva e a necessidade de os homens se entenderem para garantir a sua sobrevivência. Esta análise sublinhará a relação intrínseca entre uma dinâmica de conflito e o inevitável desenvolvimento das disposiçóes naturais do homem em direcção a um estado de mútua concórdia.
\end{abstract}

PALAVRAS-CHAVE: Kant. Filosofia política. Antagonismo. Guerra. Paz.

\section{BREVE NOTA INTRODUTÓRIA}

Ao redigir um artigo que procura avaliar a relevância do conceito de antagonismo na Filosofia Política kantiana, parece apropriado iniciá-lo com uma questão propedêutica: saber se existe propriamente uma "Filosofia Política” na obra kantiana. Trata-se de uma importante questão programática,

1 Este artigo é resultado de uma investigação de Pós-Doutoramento financiada pela Fundação para a Ciência e Tecnologia, do Ministério da Ciência e da Tecnologia de Portugal (SFRH/BPD/64211/2009). Gostaria de agradecer os comentários feitos por um parecerista anónimo a uma primeira versão deste texto, e também a Leonel Ribeiro dos Santos, Viriato Soromenho-Marques e Fernando Silva, pelas sugestôes e discussōes sobre este trabalho.

${ }^{2}$ Professor Auxiliar Convidado na Faculdade de Letras da Universidade de Lisboa, onde ensina Filosofia Social e Política e História das Ideias na Europa Contemporânea. Trabalha actualmente num pós-doutoramento sobre Federalismo Moderno e Contemporâneo, financiado pela FCT (Portugal). Doutorou-se em Filosofia Política com uma tese sobre o pensamento político de James Madison. Membro do Centro de Filosofia da Universidade de Lisboa. As suas publicaçóes e conferências centram-se sobretudo no federalismo americano e na filosofia política do séc. XVIII. E-mail: josegomesandre@gmail.com 
pois não faria sentido avançarmos com a análise de uma noção num determinado contexto temático, sem termos fundamentado devidamente a existência de tal contexto. Essa cautela metodológica justifica-se em especial pelo facto de, durante décadas, os estudiosos de Kant terem respondido negativamente àquela interrogação, valendo-se de dois argumentos principais: a inexistência de um tratado sistemático dedicado à análise do fenómeno político, em trâmites semelhantes às grandes obras críticas; e o (pretenso) facto de os textos kantianos sobre questóes políticas remeterem para o âmbito estrito da Populärphilosophie, bem ao jeito do último quartel do século XVIII, em incursôes mais ou menos ligeiras sobre circunstâncias históricas específicas (o reinado de Frederico II da Prússia, a Revolução Francesa etc.), incursões essas que, porém, se situariam à margem da filosofia crítica bem como do sistema especulativo kantiano propriamente dito $^{3}$.

Esses raciocínios não resistem, contudo, a um olhar mais atento à obra do Professor de Königsberg, potenciado por uma nova geração de comentadores que, sobretudo a partir da década de 1970, alertou não só para a riqueza dos escritos kantianos no domínio político-filosófico, como também para a existência de uma grande diversidade de conceitos e linhas argumentativas nesses textos supostamente "menores", que se relacionavam com o espírito da filosofia crítica, não podendo, por isso, uma análise sustentada continuar a separar as observaçóes kantianas sobre questôes políticas da sua obra remanescente.

Nessa matéria, é urgente superar as limitações inerentes a uma abordagem neopositivista, que parece apenas reconhecer a existência de uma reflexáo pertinente no quadro de uma exposição sistemática e cientificamente exaustiva de um determinado tema. Tal abordagem em tudo difere do paradigma setecentista (e até anterior), quando a filosofia política se movimentava em territórios difusos e plurais (mesmo quando o termo ainda não tinha sido inventado), estando presente nas obras de Leibniz, Rousseau ou Kant, sem que estes tivessem sentido particular necessidade de a definir especificamente ou de a isolar do seu restante corpo especulativo. Nesse sentido, o facto de pensadores como Kant reflectirem sobre problemas eminentemente políticos a par de outras consideraçóes disciplinares não desvaloriza as suas observaçóes nem nega a existência de um quadro temático conceptualmente organizado e coeso.

${ }^{3}$ Cf. um exemplo célebre desse tipo de desvalorizaçôes: "Quel que soit l'intérêt par les opuscules de philosophie de l'histoire, il faut reconnaître, qu'ils demeurent en marge de l'œuvre kantienne proprement dite. Le philosophe s'y exprime plus librement, sans doute, mais précisément parce que sa pensée est alors moins intégrée à son système" (BRUCH, Jean-Louis. La Philosophie Religieuse de Kant. Paris: Aubier Montaigne, 1968, p. 234). 
Por outro lado, mesmo aceitando que a filosofia política kantiana seja expressa em condiçóes peculiares (marcadas pela dispersão e assistematicidade), o simples facto de as suas noçôes e doutrinas fundamentais reconduzirem aos demais conceitos e teses nucleares da filosofia crítica deveria ser suficiente para admitir a pertinência e relevância das suas observaçôes, naquele domínio específico. $\mathrm{Na}$ verdade, as grandes formulaçôes no campo do político e do jurídico estão inextrincavelmente ligadas ao restante corpus filosófico kantiano, o qual aspira tanto no âmbito gnosiológico e moral, como no político, à realização máxima da razão (ou seja, à edificação de uma comunidade racional de indivíduos livres). Assim sendo, a filosofia política não pode deixar de ocupar um lugar proeminente, na obra kantiana tout court ${ }^{4}$.

\section{UM ANTAGONISMO CRIADOR}

Uma vez clarificada essa questão introdutória, podemos deter-nos na análise do conceito de antagonismo. Antes de mais, é necessário expurgá-lo de definiçóes equívocas, habituais no discurso coloquial e ocasionalmente presentes até mesmo em investigaçóes especulativas, que tendem a identificar a noção de antagonismo com a ideia de incompatibilidade, de oposição paralisante, traduzindo a presença de uma força negativa, primordialmente impeditiva ou anulatória. Ora, na filosofia kantiana, somos confrontados com uma leitura mais abrangente da ideia de antagonismo, a qual não se esgota nessa proposição eminentemente bloqueadora ou derrogatória, como nos mostra o tratado Versuch den Begriff der Negativen Grössen in die Weltweisheit einzuführen [Uma Tentativa de Introduzir o Conceito de Quantidades Negativas na Sabedoria Mundana], de 1763.

Nesse opúsculo, Kant considera existirem dois tipos de oposição. A primeira implica que se afirme de um objecto uma propriedade e simultaneamente a negação da mesma. Neste caso, nada de verdadeiro ou concreto se pode inferir, sendo a conclusão de tal premissa uma incoerência absoluta, um nibil negativum irrepresentabile 5 . A utilização do vocábulo "antagonismo" em sentido tradicional remete essencialmente para essa

\footnotetext{
${ }^{4}$ Sobre o importante papel da Filosofia Política na obra kantiana, cf., entre muitos outros: WILLIAMS, Howard. Kant's Political Philosophy. Oxford: Basil Blackwell, 1985, p. i e ss.; cf. ainda: ARENDT, Hannah. Lectures on Kant's Political Philosophy. Chicago: University of Chicago Press, 1989, p. 7 e ss.

${ }^{5}$ KANT, Immanuel. Versuch den Begriff der Negativen Grössen in die Weltweisheit einzuführen, Gesammelte Schriften. Ed. Königliche Preussische Akademie der Wissenschaften (doravante Ak.), vol. 2, p. 171.
} 
acepção, designando a existência de duas forças que mutuamente se anulam, revelando-se essa coexistência como necessariamente improdutiva.

No texto de 1763 , Kant alerta, porém, para a existência de um outro tipo de oposição, mediante a qual se afirmam duas propriedades contrárias de um mesmo objecto, sem que ocorra uma incoerência lógica, dado que as propriedades nele reconhecidas não são reciprocamente exclusivas, mas meramente contrapostas. A confrontação de duas forças ou propriedades contrárias assumiria assim a aparência de um tipo de paradoxo, embora designasse na verdade simplesmente uma ambivalência estruturante, um antagonismo i.e., a conciliação de duas características ou postulados opostos no quadro de um conceito significativo, que não seria necessariamente vazio ou estéril.

Ainda que essas observaçóes digam respeito fundamentalmente a juízos lógicos, podemos sem dúvida encontrar nelas, de forma embrionária, as bases teóricas de elementos doutrinais fundamentais do pensamento político e antropológico kantiano, nomeadamente a ideia da sociabilidade insociável como matriz da essência humana, bem como a noção de progresso pensada enquanto desígnio histórico que, todavia, brota da guerra e da discórdia entre os homens. Num e noutro caso, é o conceito de antagonismo (pensado como oposição aparentemente paradoxal) que explica a passagem de um aparente dualismo a uma dialéctica transformadora do humano, do social e do político - ficando assim sublinhada a sua relevância na especulação kantiana.

Não nos deve surpreender, por isso, que a noção de antagonismo esteja desde logo presente nos textos pré-críticos, sob várias formas (explícitas, implícitas ou metafóricas). Aí procede Kant a uma análise das leis da natureza e do funcionamento geral do cosmos, com repetidas mençôes à existência de uma espécie de dialéctica natural, um modelo dinâmico de organização do universo, repleto de forças contrastantes que produzem ora equilíbrios decisivos à sustentabilidade do cosmos, ora novas flutuaçóes e movimentos que brotam desse diálogo de energias antagónicas. Kant relacionará a descrição desse universo inquieto, que se expande a partir de um conflito interno, com a ideia de uma "Fénix da Natureza" [Phönix der Natur], referindo-se ainda às "[...] cenas revoltosas que se encontram numa gota de matéria", as quais não deixam de lhe causar um grande espanto face à "[...] peculiar majestade $\mathrm{e}$ dignidade de tal vista"

6 “[...] wenn ich die Ränke, die Gewalt und die Szene des Aufruhrs in einem Tropfen Materie ansehe, und erhebe von da meine Augen in die Höhe, um den unermeßlichen Raum von Welten wie von Stäubchen wimmeln zu sehen, so kann keine menschliche Sprache das Gefühl ausdrücken, 
O que merece particular destaque nessa concepção é o facto de Kant perspectivar tais dinâmicas opostas como um instrumento produtivo e não como um mecanismo de bloqueio. Onde um primeiro olhar descortina uma contradição paralisadora (senão mesmo destrutiva), o nosso filósofo encontra ao invés um antagonismo criador, um processo pelo qual a contraposição de forças adversas gera algo de essencialmente novo - correspondendo a essa dialéctica a própria ideia de expansão orgânica do universo. Essa luta não constitui por conseguinte uma tragédia a lamentar, uma vez que o conflito fundamental nela envolvido é afinal condiçáo necessária à renovação dos processos criativos da natureza. $\mathrm{O}$ conceito de antagonismo parece repousar assim sobre a ideia de paradoxo, mas não fica por definição remetido ao simples confronto perpétuo de duas forças contraditórias, sendo antes o ponto de partida para a gestação de novos dinamismos ${ }^{7}$.

O núcleo essencial dessas teses será retomado no célebre opúsculo de 1784, Idee zu einer allgemeinen Geschichte in weltbürgerlicher Absicht [Ideia de uma História Universal com um Propósito Cosmopolita], obra na qual Kant numa abordagem aliás bem consentânea com a filosofia crítica - considera a possibilidade de inserir o conceito de progresso numa narrativa racional da história. Devido aos limites das capacidades cognitivas dos indivíduos e da existência humana em geral, tal visão teleológica não pode assentar em garantias absolutas, mas se torna pensável enquanto ideia da razão, face à qual surge simultaneamente como um dever prático e um objectivo desejável. Tal narrativa histórica se apoia em dois princípios fundamentais: a ideia de que as disposiçóes naturais dos sujeitos estão destinadas a um desenvolvimento integral; e o facto de esse gradual desenvolvimento ocorrer por via de uma série de dinâmicas antagónicas, cujo papel primordial é justamente desencadear tal processo evolutivo.

Eis-nos de novo diante da categoria de "antagonismo", entendida como instrumento criativo crucial, sobre o qual Kant discorre no referido texto, a propósito de uma reflexão essencialmente antropológica. Diz-nos o filósofo alemáo que o grande factor desencadeador do mencionado aperfeiçoamento

was ein solcher Gedanke erregt, und alle subtile metaphysische Zergliederung weichet sehr weit der Erhabenheit und Würde, die einer solchen Anschauung eigen ist" (KANT, Immanuel. Der Einzing Mögliche Beweisgrund zu einer Demonstration des Daseins Gottes, Ak., vol. 2, p. 117). A expressão "fénix da natureza" ocorre em Allgemeine Naturgeschichte und Theorie des Himmels, Ak., vol. 1, p. 321.

7 Sobre o uso do conceito de "antagonismo" nos textos pré-críticos, cf. SANER, Hans. Kant's Political Thought. Chicago: University of Chicago Press, 1973, p. 7 e ss. 
do género humano é um tipo de conflito peculiar - o antagonismo existente no seio do próprio homem, que toma o nome de "sociabilidade insociável":

$\mathrm{O}$ meio de que a natureza se serve para levar a cabo o desenvolvimento de todas as disposiçóes [do homem] é o seu antagonismo na sociedade [...]. Entendo aqui por antagonismo a sociabilidade insociável dos homens, isto é, a sua tendência para entrarem em sociedade, tendência que, no entanto, está unida a uma resistência universal que ameaça dissolver constantemente a sociedade. ${ }^{8}$

Essa célebre expressão designa, portanto, o conflito interno que subsiste no homem, dividido entre o seu desejo de viver numa comunidade de iguais, onde se reconhece a si próprio como indivíduo e onde sente ser possível um maior aperfeiçoamento das suas capacidades naturais, e a propensão para o isolamento (onde exerce, afinal, um absoluto e irrestrito domínio sobre si próprio e o mundo que o rodeia), fugindo aos entraves que os outros seres humanos representam face à idealização e realização das suas pretensôes.

Tal "sociabilidade insociável" é a expressão mais acabada da ideia de "antagonismo" tal como Kant a concebe, o que aliás se esclarece ao verificarmos a origem etimológica dessa noção. Trata-se de uma combinação do grego óv $\tau \alpha$ (face a face) e ó $\gamma$ ovía (luta), o que sublinha o facto de não estarmos apenas perante uma ambivalência estática de duas realidades opostas que coexistem pacificamente no homem, mas, pelo contrário, diante de uma "luta face a face" entre a tendência para entrar em sociedade e a resistência que nela o homem encontra. Essa dinâmica é, por conseguinte, a origem de uma dialéctica que desencadeia o despertar do indivíduo, que o acicata a desenvolver os seus talentos, a competir e a cooperar com os outros indivíduos para aperfeiçoar as suas disposições naturais? .

\footnotetext{
8 "Das Mittel, dessen sich die Natur bedient, die Entwickelung aller ihrer Anlagen zu Stande zu bringen, ist der Antagonism derselben in der Gesellschaft, [...]. Ich verstehe hier unter dem Antagonism die ungesellige Geselligkeit der Menschen; d. i. den Hang derselben, in Gesellschaft zu treten, der doch mit einem durchgängigen Widerstande, welcher diese Gesellschaft beständig zu trennen droht, verbunden ist" (Idee zu einer allgemeinen Geschichte in weltbürgerlicher Absicht, Ak., vol. 8, p. 20).

${ }^{9}$ Caso o homem não possuísse esse antagonismo, continuaria a ser dotado dessas faculdades naturais, mas estas ficariam para sempre ocultas, tendendo o homem, enquanto género, a uma estagnação. Porém, e eis um enorme porém, o homem possui essa insociabilidade, que funciona como elemento desequilibrador duma potencial situação harmoniosa inicial. Essa resistência que ele encontra na sociedade, para a qual se sente naturalmente inclinado, esse antagonismo radical, provoca uma luta interior que resulta num despertar das disposiçóes originais.
} 
Nesse sentido, a "sociabilidade insociável" constitui um primeiro motor na história do progresso, embora, ao mesmo tempo, ela lance desde logo uma nuvem sombria sobre a própria ideia de intersubjectividade, condicionando todas as relaçóes sociais a uma lógica que tem tanto de desejo autêntico de interacção como de cálculo egoísta. Com efeito, é sobretudo a necessidade que cada sujeito tem de aperfeiçoar as suas capacidades próprias, de melhor garantir a sua segurança e de sobreviver num meio natural perigoso que o dirigem a procurar e a manter uma vida em sociedade.

Essa ambiguidade hostil - como todas as lógicas antagónicas em Kant - não é, porém, estática na sua essência, sendo outrossim revestida de uma produtividade fundamental, que se transforma num imperativo teóricoprático: o dever de sujeitar esse conflito antropológico a uma ordem social, política e legal que discipline os impulsos egoístas dos homens e permita uma subsistência e convivência dos mesmos, de forma organizada, pacífica e tendencialmente cooperante. Pois o género humano está afinal condenado a realizar todas as suas potencialidades - o que torna também necessário alcançar um ideal político o mais favorável possível à sua sobrevivência e ao seu aperfeiçoamento.

\section{Paz E guerra: o antagonismo POR EXCELÊNCIA}

É no quadro dessa reflexão sobre a necessidade de uma coação institucional - que brota afinal da própria dinâmica do conflito - que Kant introduz as noções de "paz" e "guerra", par conceptual que traduz o mais acutilante e especulativamente profícuo tratamento da ideia de antagonismo, no âmbito da meditação político-filosófica kantiana. No entender do Professor de Königsberg, a paz é vista como a tarefa maior e última do progresso, estádio possível pelo estabelecimento de uma concórdia entre os homens, por sua vez alicerçada no projecto sociopolítico-jurídico anteriormente aludido. A paz seria assim o derradeiro objectivo, e simultaneamente a trave-mestra, de todo o projecto político kantiano, designando não tanto a suspensão dos conflitos existentes, mas sim o condicionamento dos mesmos (quer no nível das relaçóes intersubjectivas, quer interestatais) ao ordenamento supremo da lei, à ideia de uma convivência sustentada em relaçóes jurídicas firmes e universais, criando condiçôes para a evolução de cada indivíduo - e da comunidade em geral num quadro social, político e jurídico respeitado por todos. 
Sobre a concretização de tal projecto, fala-nos Kant timidamente ainda na Idee, e posteriormente de forma mais detalhada na Metaphysik der Sitten [Metafísica dos Costumes] e em Zum ewigen Frieden [Para a Paz Perpétua], identificando a necessidade de edificar a mencionada ordem política e legal, num plano tripartido:

- no nível interno dos próprios Estados (capaz de promover a segurança e a liberdade dos seus habitantes);

- no nível das relaçóes entre os Estados (mediada por uma grande federação internacional - a "Liga de Povos") e, em última instância;

- no nível da criação de uma verdadeira "ordem mundial" (promovendo um direito cosmopolita que relevasse a posição do indivíduo como "cidadão do mundo" $)^{10}$.

$\mathrm{Na}$ perspectiva kantiana, uma primeira condição para a paz é, com efeito, a existência de uma ordem constitucional interna onde sejam respeitados os direitos e liberdades fundamentais dos indivíduos, o que por sua vez exige um modelo republicano - o qual consagre a separação de poderes e o primado da lei, e submeta a decisão sobre a paz e a guerra, tradicionalmente colocada nas mãos dos soberanos absolutos, ao juízo dos representantes do povo.

Atente-se: Kant náo está a sustentar que a implantaçáo de um regime republicano em cada Estado seja sinónimo de realização da paz em nível externo, mas sim a afirmar que um projecto para uma remodelação das relaçóes internacionais consigna um plano mais vasto: uma reforma das instituiçóes, estruturas e instrumentos jurídico-constitucionais em um nível interno dos Estados. Por conseguinte, uma "nova ordem internacional" pressupóe, antes de mais, uma "nova ordem nacional", onde esteja implementado um sistema representativo de governo, onde seja impraticável um comportamento arbitrário do soberano e onde se respeitem a liberdade e a dignidade dos indivíduos.

${ }_{10}$ Cf. KANT, Immanuel. Metaphysic der Sitten, Ak., vol. 6, p. 311-318; Zum ewigen Frieden, Ak., vol. 8, p. 348-360. Sobre a íntima conexão entre essas três exigências, cf. SANTOS, Leonel Ribeiro dos. "Republicanismo e cosmopolitismo. A contribuição de Kant para a formação da ideia moderna de federalismo". In: LEAL, Ernesto Castro (Ed.). O Federalismo Europeu. História, Política e Utopia. Lisboa: Colibri, 2001, p. 57: "Três programas, portanto, estáo implicados neste projecto kantiano: o programa republicano no interior de cada Estado; o programa federalista na relação entre Estados; e o programa cosmopolita na relaçáo de todos os Estados com os cidadáos de qualquer Estado. Republicanismo, Federalismo, Cosmopolitismo. Podem os intérpretes pretender desligá-los. Para Kant eles nấo só são aspectos de um mesmo projecto, como cada um depende de todos os outros.” 
A obtenção de uma efectiva concórdia mundial pressupóe, contudo, uma efectivação da relação entre os Estados através de um projecto federal, porque a segurança interna será sempre periclitante, enquanto permanecer dependente das ameaças externas. Estas não devem ser combatidas com um enclausuramento da nação sobre si própria, uma espécie de solipsismo político - visto que este a tornaria apenas refém das suas insuficiências e um alvo fácil para a ambição e poderio de outros Estados ou alianças mais poderosas. Para Kant, a paz só pode concretizar-se num plano global que integre as várias naçôes autónomas numa associação federal cooperante:

[...] [o estado de paz] náo pode estabelecer-se ou garantir-se sem um pacto entre os povos: - tem, portanto, de existir uma federação de tipo especial, a que se pode dar o nome de federaçáo da paz [Friedensbund (foedus pacificum)] [...]. Esta federação não se propóe obter o poder do Estado, mas simplesmente manter e garantir a paz de um Estado para si mesmo e, ao mesmo tempo, a dos outros Estados federados $[\ldots]^{11}$.

Na génese do projecto federal - cujo objectivo último é criar uma convivência pacífica e saudável entre as diversas nações - está, por conseguinte, um instinto de sobrevivência, um imperativo natural primitivo, que compele o indivíduo em particular, e os Estados, em geral, a criarem uma situação de concórdia que ponha fim aos conflitos permanentes, cuja violência teria como consequência, em última instância, a sua própria aniquilação. Esse impulso primitivo confunde-se com um estranho e inquietante "plano oculto da natureza" [eines verborgenen Plan der Natur], a que anteriormente aludimos $^{12}$, que lança os homens originariamente no seio da discórdia e da guerra, próprias do estado de natureza, apenas para o obrigar, perante a força das circunstâncias, a superar e a inverter essa tendência natural, construindo um projecto de acordo mútuo, i.e., subordinando-se a um poder que reprime os conflitos e submete as potenciais relaçôes de discórdia a uma lei comum que rege os indivíduos, e cuja legitimidade e eficácia advêm do facto de serem eles mesmos que a criam, consentem e à qual livremente se submetem.

\footnotetext{
11 “[...] [den Friedenszustand] ohne einen Vertrag der Völker unter sich, nicht gestiftet oder gesichert werden kann: - so muß es einen Bund von besonderer Art geben, den man den Friedensbund (foedus pacificum) nennen kann, [...]. Dieser Bund geht auf keinen Erwerb irgend einer Macht des Staats, sondern lediglich auf Erhaltung und Sicherung der Freiheit eines Staats, für sich selbst und zugleich anderer verbündeten Staaten [...]”. (KANT, Immanuel. Zum ewigen Frieden, Ak., vol. 8, p. 356).

${ }^{12}$ Cf. KANT, Immanuel. Idee zu einer allgemeinen Geschichte in weltbürgerlicher Absicht, Ak., vol. 8, p. 27.
} 
Kant não fundamenta, portanto, o seu raciocínio numa qualquer crença inabalável na humanidade, mas antes num imperativo da razão prática e nos desígnios da natureza, a qual confronta os seres humanos com a necessidade de estabelecer uma situação de concórdia:

[...] todos os homens devem poder apresentar-se à sociedade, devido ao seu direito à propriedade comum da superfície da Terra, sobre a qual ninguém detém originariamente mais direito do que outrem; e em relação à qual, devido à sua superfície esférica, os homens não podem estender-se até ao infinito, devendo finalmente suportar-se uns aos outros. ${ }^{13}$.

Em certo sentido, o que está aqui em causa é reconhecer que os homens estão condenados a entender-se, não porque são seres naturalmente benevolentes uns com os outros, mas porque sem esse compromisso resta a guerra de todos contra todos - e com ela, mais tarde ou mais cedo, a destruiçáo do género humano.

É nesse contexto que Kant fala de um inevitável caminho conducente à "hospitalidade universal”, o alicerce de uma solidária e fraterna convivência entre os homens, os quais, independentemente das suas inclinaçóes naturais, acabam forçados pela finitude da vida, dos recursos terrestres e, enfim, da necessidade de mútua coexistência, a finalmente suportarem-se uns aos outros. De alguma forma, é a natureza que permite efectuar a passagem de um plano estritamente racional para uma concretização material dessa exigência imposta pela razão prática, a qual deve visar em última instância a um projecto de teor assumidamente universalista.

Com efeito, Kant começa por se referir a um federalismo de tipo essencialmente defensivo (o mínimo acordo exigível para que a paz triunfe entre os Estados). Todavia, o derradeiro desígnio da natureza, este fim último da paz (Endzweck), requer um projecto mais ambicioso: a criação de uma verdadeira "república mundial" (Kant menciona a hipótese de englobar, numa federação, "todos os povos da Terra") e o surgimento de uma cidadania cosmopolita. Esse processo, que Kant perspectiva como um paulatino aperfeiçoamento das relaçôes entre os Estados e os seus cidadãos, culminaria, dessa forma, com a edificação de uma "União de todos os Estados mundiais" e com a elevação do

\footnotetext{
13 "[...] allen Menschen zusteht, sich zur Gesellschaft anzubieten, vermöge des Rechts des gemeinschaftlichen Besitzes der Oberfläche der Erde, auf der, als Kugelfläche, sie sich nicht ins Unendliche zerstreuen können, sondern endlich sich doch neben einander dulden zu müssen, ursprünglich aber niemand an einem Orte der Erde zu sein mehr Recht hat, als der andere" (KANT, Immanuel. Zum ewigen Frieden, Ak., vol. 8, p. 358).
} 
indivíduo a cidadão de um estado universal da humanidade, o mais alto ideal da política, da moral e do direito ${ }^{14}$.

A tónica optimista que encerra essa lógica argumentativa tentou vários comentadores a descreverem a proposta kantiana como ingénua, esquecendo os mesmos que essa teleologia do progresso não assenta numa bonomia humana, mas antes numa realidade que está nos antípodas de uma propensão natural para o bem: a ideia de guerra. Com efeito, é o conflito - endémico à natureza humana - que desencadeia todo o processo de construção de uma ordem social e política sustentável. É o antagonismo intersubjectivo que lança o homem numa gradual evolução das suas disposiçóes, que o constrange a aperfeiçoar os seus métodos de socialização e, simultaneamente, de combate, de afirmação diante do outro e de conquista do seu território. Pelo que a guerra não surge aqui como mera metáfora de uma "luta interna individual", mas sim como a consequência lógica do conflito que habita o humano, traduzindo-se em contendas permanentes entre pequenos grupos, tribos, regiốes ou Estados.

Tais contendas não são, contudo, meros processos de destruição definitiva, uma espécie de concretização objectiva do negativo. $\mathrm{Na}$ verdade, como afirmámos previamente, elas são antes dinâmicas criativas, momentos de gestação de algo essencialmente novo, que ora tomam um sentido predominantemente prático, ora teórico (sendo nesta última acepção, sobretudo, uma tomada de consciência). Sobre o primeiro tópico fala-nos Kant em Zum ewigen Frieden, ao relatar o modo como a guerra induziu o homem a estender-se geograficamente, a aprender a tirar o maior proveito dos objectos, a desenvolver as suas próprias capacidades naturais de combate e, num momento posterior, a elaborar disposiçôes legais que enquadrassem essas mesmas relaçóes conflituosas ${ }^{15}$.

A segunda acepção é, afinal, uma derivação lógica da continuação de tais contendas, cujos efeitos colaterais (corrida ao armamento, espiral de violência, gastos crescentes), associados à natureza destruidora da própria guerra, acabam por confrontar o homem com a necessidade de a controlar e, por fim, de a extinguir por completo, sob pena de pôr em risco a sobrevivência da própria

\footnotetext{
${ }^{14}$ Cf. KANT, Immanuel. Zum ewigen Frieden, Ak., vol. 8, p. 354-360; Idee zu einer allgemeinen Geschichte in weltbürgerlicher Absicht, Ak., vol. 8, p. 27-28; Metaphysic der Sitten, Ak., vol. 6, p. 350-351.

${ }^{15}$ Cf. "Ihre [die Natur] provisorische Veranstaltung besteht darin: daß sie 1) für die Menschen in allen Erdgegenden gesorgt hat, daselbst leben zu können; - 2) sie durch Krieg allerwärts hin, selbst in die unwirtbarste Gegenden, getrieben hat, um sie zu bevölkern; 3) durch eben denselben sie in mehr oder weniger gesetzliche Verhältnisse zu treten genötigt hat" (KANT, Immanuel. Zum ewigen Frieden, Ak., vol. 8, p. 363).
} 
humanidade. A guerra começa por ser um princípio de desenvolvimento, mas em última instância ela é um conflito ilimitado, transgressão de limites por definição. Sem barreiras que a limitem, e que por último a anulem, ela não pode deixar de destruir o processo de desenvolvimento que iniciou, tornando-se a grande adversária da civilização que ajudou a construir.

Onde o conceito de guerra recebe uma abordagem verdadeiramente nova com o pensamento kantiano é nessa descrição de uma ambivalência fundamental, de uma realidade que contém em si mesma a solução para o problema que ela própria desde logo coloca. Com efeito, ao constituir-se como força destrutiva por excelência - que, progredindo de forma exponencial, só poderia trazer a aniquilação da humanidade (e possivelmente do próprio planeta) - a guerra representa ab initio um desafio que por sua vez só pode ter igualmente uma resposta: a necessária supressão (e consequente superação) do facto problemático em questão. Por outras palavras, a destruição inevitável que ela anuncia torna autoevidente a urgência de a extinguir, para que o homem garanta a sua própria subsistência.

Ao homem simplesmente não restam, pois, alternativas senão formar um edifício político-jurídico que garanta a paz entre as naçóes, procedendo de modo análogo àquele momento instaurador da sociedade civil, quando os indivíduos renegam a sua liberdade natural irrestrita para encontrarem a protecção possível pela existência de leis públicas e de um Estado consolidado:

Assim como a violência omnilateral e a miséria que daí deriva levaram necessariamente um povo à resoluçáo de se submeter ao constrangimento que a própria razáo lhe prescreve como meio, a saber, a lei pública, e a entrar numa constituição civil, assim também a miséria resultante das guerras permanentes, em que os Estados procuram uma e outra vez humilhar ou submeter-se entre si, deve finalmente levá-los, mesmo contra vontade, a ingressar numa constituição cosmopolita $[\ldots]^{16}$.

Todo esse esquema argumentativo é assim perpassado por algo que poderíamos designar como dialéctica do conflito - um processo de maturação

\footnotetext{
16 "So wie allseitige Gewalttätigkeit und daraus entspringende Not endlich ein Volk zur Entschließung bringen mußte, sich dem Zwange, den ihm die Vernunft selbst als Mittel vorschreibt, nämlich dem öffentlicher Gesetze zu unterwerfen, und in eine staatsbürgerliche Verfassung zu treten: so muß auch die Not aus den beständigen Kriegen, in welchen wiederum Staaten einander zu schmälern oder zu unterjochen suchen, sie zuletzt dahin bringen, selbst wider Willen, entweder in eine weltbürgerliche Verfassung zu treten [...]". (KANT, Immanuel. Über den Gemeinspruch: Das mag in der Theorie richtig sein, taugt aber nicht für die Praxis, Ak., vol. 8, A278, 279).
} 
do ser humano e das instituiçôes por si criadas, cujo começo se encontra no mal em si naturalmente existente e na guerra que ameaça consumir as relaçôes inter-humanas. O caminho da paz alcança-se efectivamente pela guerra e pelo mal, instrumentos de que a natureza se vale para espicaçar o desenvolvimento humano, incitando-o a sair de uma letargia confortável, semeando a discórdia e difundindo o ódio mútuo apenas para que, no fim de contas, a humanidade se possa aproximar gradualmente de uma relação harmoniosa. Sobre a produtividade do mal trata Kant amplamente, no Opus Postumum, em aforismos que expressam na sua crueza e simplicidade a riqueza conceptual das doutrinas previamente expostas pelo autor alemão:

$\mathrm{O}$ homem realiza o que tem de ser desenvolvido a partir do mal. O mal constrange para o bem"; "Ele [o homem] necessita dos males [die Übel] como espora para o vencer da sua preguiça e desenvolvimento de todos os talentos (o mal [das Böse] é a animalidade na medida em que ela torna necessário o desenvolvimento da humanidade) [...]"; "Tudo começa com o mal... O progresso da Natureza dirige-se para a completude de todas as perfeiçôes, para isso encontram-se os embriōes [no homem])"; "A determinaçáo [natural] do homem é o desenvolvimento de todos os talentos e a felicidade e bondade fundadas sobre a mais elevada arte. Para isso serve-se a Natureza da dor e do mal que ela nos inflige [... $]^{17}$.

17 "Der Mensch macht, dass es auch dem Bösen entwickelt werden muss. Das Böse zwingt zum Guten.”, Reflexion 1521, Ak., vol. 15, p. 890; "Er bedarf die Übel zum Sporn, zu überwältigung seiner Faulheit und Entwicklung aller talente (Das Böse ist die Thierheit, so fern sie die Entwicklulung der humanitaet nothwendig macht.)", Reflexion 1423, Ak, vol. 15, p. 621; "Alles fängt vom Übel an... Der Fortschritt der Natur geht auf die Vollendung aller perfectionen, dazu die Keime liegen.”, Reflexion 1412, $A k$, vol. 15, p. 615; "Die [Natur] Bestimmung des Menschen ist die Entwikelung aller Talente und die auf die hochste Kunst gegründete Glükseeligkeit und Gutartigkeit. Dazu bedient sich die Natur des Schmerzens und der Übel, die sie uns anthut, noch mehr [...]”. (Reflexion 1454, $A k$, vol. 15, p. 636).

O tema da "dinâmica antagónica", ou melhor, de como uma lógica de forças opostas pode ser geradora de novos sentidos, é um tema relativamente comum no século XVIII, estando presente nas obras de Turgot, Joseph Priestley, Adam Ferguson, Bernard de Mandeville, Adam Smith, entre outros. Tal coincidência de opiniōes pode explicar-se, em boa parte, pelo contexto histórico em que viveram esses autores, marcado pelo optimismo próprio das Luzes, que todavia necessitava de ser conciliado com o problema da existência do mal e a verificação fáctica de um quadro social, político, económico e científico ainda bastante precário. De certo modo, todos esses autores contemplaram, assim, a possibilidade de se verificar uma dialéctica a partir de elementos originários conflituantes, por vezes mesmo essencialmente negativos. Com efeito, as várias teses dos autores referidos nesse domínio constituem como que variantes desse mesmo tema primordial (a "produtividade do antagonismo"), ora na relaçáo com a ideia de progresso (resultado de sucessivos e encadeados conflitos - como em Turgot, Priestley ou Ferguson), ora na ligação com uma leitura político-económica (sendo os benefícios públicos possíveis a partir da luta entre sujeitos que buscam ganhos individuais - como em Mandeville ou Adam Smith). Como é sabido, essas ideias serão posteriormente retomadas na obra de Hegel, que com o seu conceito de "astúcia da razão" estabelece a possibilidade de correlação entre um quadro 


\section{Será Kant utópico?}

Ao estabelecer uma conexão directa e indissociável entre a guerra (expressão máxima de violência e destruição) e a paz (estado de concórdia apenas possível justamente com a extinção da guerra), não estará Kant a incorrer numa contradição? Assim sugerem alguns comentadores, com destaque para Alexis Philonenko, que, num célebre estudo sobre o pensamento kantiano, alerta precisamente para a existência de um paradoxo difícil de aceitar: o facto de Kant sustentar a ideia de progresso e a possibilidade da paz numa concepção particularmente pessimista do ser humano, o que lança, no mínimo, a suspeição de que tais indivíduos jamais sejam capazes de edificar um estado de concórdia entre $\mathrm{si}^{18}$. Trata-se, em suma, da velha questão de saber como pode algo de táo essencialmente bom (como a paz) ser produzido a partir de algo táo naturalmente mau, como o homem.

Essas interrogaçôes são ao mesmo tempo pertinentes e deficitárias. Por um lado, padecem de uma deficiência crassa - quando aplicada ao pensamento kantiano - ao olvidarem a existência de uma ambivalência antropológica (por oposição a uma visão unidimensional das paixôes humanas). Nesse sentido, focam a sua atenção numa natureza corruptível e essencialmente negativa, quando na verdade o homem é um misto de virtudes e defeitos, sendo marcado pela "sociabilidade insociável" que anteriormente descrevemos. Ademais, tal leitura insiste em encarar a ideia de "paradoxo" sob um prisma demasiado tradicional, i.e., como contradição paralisante, negação lógica que invalidaria novas conclusóes, novos produtos. Ora, como temos insistido ao longo deste ensaio, a ideia de antagonismo em Kant não pode ser inserida em tal paradigma interpretativo, uma vez que ela é em si própria um factor dinâmico, um estímulo à geração de novos sentidos, novas forças, novos processos.

Em suma, onde Philonenko julga encontrar um paradoxo imobilizante, desvenda-se na verdade o segredo da concepção kantiana, já que tal paradoxo não passa de uma lógica antagónica produtiva, capaz de superar a aparente contradição dos termos, justamente porque é a partir de tal oposição que se constrói um processo vigoroso e necessário. Guerra e paz complementam-se precisamente, porque são princípios antagónicos, desencadeando a primeira na

de conflito primevo e uma dialéctica criadora, uma vez que essa discórdia inicial sempre gera novos sentidos, que estão na base do progresso histórico.

${ }^{18}$ Cf. PHILONENKO, Alexis. "Kant et le problème de la paix". In: Essai sur la philosophie de la guerre. Paris: Vrin, 2003 [1. ed. 1976], p. 39 e ss. 
sua figuração destruidora a absoluta necessidade da segunda, sua superação e negação, fim último de uma dialéctica fundada na noção de conflito.

Contudo, as observaçóes de Philonenko são certeiras, quando apontam para uma dimensão problemática do argumento kantiano - a forma como este descreve a ideia de paz como uma necessidade indiscutível (que equivaleria na prática à supressão de todas as lógicas conflituosas) advertindo, ao mesmo tempo, não só para a extrema dificuldade de tal projecto, como para a impossibilidade de corrigir plena e definitivamente a natureza humana. Este último aspecto é confirmado pelo próprio Kant, ao longo da sua obra, descrevendo o autor alemão como utópico e "impossível” [unmöglich] qualquer projecto político que pretendesse erradicar da natureza humana uma propensão para o mal, para o isolamento e para a autossatisfação individual, que lhe serão sempre características ${ }^{19}$.

Nesse sentido, Kant refere-se à obtenção da paz e à criação de um quadro jurídico-político vinculativo e compulsório que a sustentaria como o "[...] problema mais difícil e mais tardiamente resolvido pelo género humano"20, visto que de nada valem apelos a uma suposta bonomia da humanidade ou o desejo de transformar definitivamente o seu carácter. N'A Metafísica dos Costumes, Kant afirma mesmo que "[...] a paz perpétua (o fim último do direito das gentes na sua totalidade) é, sem dúvida, uma ideia irrealizável”21. Mas, como pode uma ideia ser, ao mesmo tempo, necessária e inatingível, inevitável e impraticável?

Eis-nos confrontados com a ideia de um antagonismo pregnante, na sua máxima expressão. Por um lado, a imperfeiçáo do real torna a concretização da paz em algo inexequível, dada a impossibilidade de modificar plenamente as paixôes humanas e os seus impulsos egoístas, ou de contornar os variados obstáculos materiais que as relações internacionais colocam à obtenção de dinâmicas de entendimento entre os Estados. Todavia, por outro lado, não permite a natureza

\footnotetext{
19 Cf. "Esta tarefa é a mais difícil de todas as tarefas; mais ainda, a sua solução perfeita é impossível: de um lenho tão retorcido, de que o homem é feito, nada de inteiramente direito se pode fazer" "Diese Aufgabe ist daher die schwerste unter allen; ja ihre vollkommene Auflösung ist unmöglich: aus so krummem Holze, als woraus der Mensch gemacht ist, kann nichts ganz Gerades gezimmmert werden". KANT, Immanuel. Idee zu einer allgemeinen Geschichte in weltbürgerlicher Absicht, Ak., vol. 8, p. 23.

20 "Dieses Problem ist zugleich das schwerste, und das, welches von der Menschengattung am spätesten aufgelöset wird" (KANT, Immanuel. Idee zu einer allgemeinen Geschichte in weltbürgerlicher Absicht, $A k$, vol. 8, p. 23).

21 "[...] so ist der ewige Friede (das letzte Ziel des ganzen Völkerrechts) freilich eine unausführbare Idee” (KANT, Immanuel. Metaphysic der Sitten, Ak., vol. 6, p. 350).
} 
- nem o consentiria a razáo - que o homem desistisse de procurar corrigir os vários conflitos interestatais, ou que se resignasse perante a "luta interna" que o consome, sendo assim impelido a procurar uma solução para tal conflito e para os efeitos nocivos que o mesmo opera na vida colectiva da humanidade.

Por conseguinte, nem as dificuldades de realizaçáo de tal projecto, nem a ausência de garantias históricas, nem ainda a impossibilidade de elaborar um juízo lógico determinativo sobre a sua exequibilidade são suficientes para tornar a paz despicienda ou descartável. Independentemente de tais consideraçóes, ou até mesmo da sua vontade, o ser humano é compelido a procurar um entendimento possivel, que não equivale a uma obrigação moral, mas a uma inevitabilidade que a própria natureza torna manifesta e a razão valida e abraça como projecto seu, convidando o homem a pensar esse progresso "como se" [als ob] ele fosse revestido de uma finalidade positiva:

Não se trata de saber se a paz perpétua é real ou algo sem sentido [Unding], e se náo nos enganaremos no nosso juízo teórico, se supusermos o primeiro; em qualquer caso, devemos agir como se ela fosse possível, ainda que porventura não o seja, e elaborar a constituição que se nos afigure mais idónea (talvez o republicanismo dos Estados em conjunto) para a alcançar e acabar com a terrível guerra $[\ldots]^{22}$.

A paz constitui assim uma ideia reguladora da razão, assumindose como necessária independentemente das circunstâncias específicas que enquadrem a sua procura. Pouco importa que as condiçóes reais do mundo se apresentem ao nosso juízo como barreiras insuperáveis (convencendo-nos a emitir uma opiniáo depreciativa sobre tal possibilidade na prática), uma vez que ela continuará a surgir para a razão como uma hipótese pensável e válida em si mesma, ou seja, como um dever que cabe ao homem perseguir, mesmo contra todas as probabilidades.

Kant oferece-nos como tal uma filosofia da paz sustentada exclusivamente em preceitos racionais. Isso não significa que o autor alemão estivesse desatento ao contexto social e político do seu tempo, nem que ignorasse a importância de criar mecanismos objectivos eventualmente conducentes à concretização da

\footnotetext{
22 "AIso ist nicht mehr die Frage: ob der ewige Friede ein Ding oder Unding sei, und ob wir uns nicht in unserem theoretischen Urteile betrügen, wenn wir das erstere annehmen, sondern wir müssen so handeln, als ob das Ding sei, was vielleicht nicht ist, auf Begründung desselben, und diejenige Konstitution, die uns dazu die tauglichste scheint (vielleicht den Republikanism aller Staaten samt und sonders) hinwirken, um ihn herbei zu führen, und dem heillosen Kriegführen [...] ein Ende zu machen" (KANT, Immanuel. Metaphysic der Sitten, Ak., vol. 6, p. 354).
} 
paz, mas sim que Kant teve o génio de cimentar a necessidade desse projecto derradeiro na validade pura inerente à razão, tornando-o imprescindível em todas as conjunturas, em todas as regióes, em todas as eras. O ditame "Es soll kein krieg sein" - verdadeira condição da paz - não deriva, portanto, de uma apreciação geopolítica ou de uma estratégia diplomática, mas antes de um imperativo racional que a natureza, como vimos antes, sistematicamente lhe confirma como indispensável:

Ora bem, a razão prático-moral expressa em nós o seu veto irresistível: não deve haver guerra; nem guerra entre ti e mim no estado de natureza, nem guerra entre nós como Estados [...], pois este não é o modo como cada um deve buscar o seu direito. ${ }^{23}$.

Esconder-se-á por detrás desse pensamento antagónico uma forma de utopia, uma espécie de crença no impossivel? Julgamos que não, por duas razões fundamentais. Em primeiro lugar, porque toda reflexão utópica pressupóe uma dicotomia radical, separando tipicamente a realidade concreta do ideal descrito, servindo este essencialmente como um modelo que o mundo real cobiça, mas que nunca poderá concretizar. A utopia acarreta, pois, uma clara divisão entre o ideal e o real, entre o teórico e o prático. O argumento kantiano transcende esse tipo de separação, relacionando o real e o prático com o ideal e o teórico, justamente porque estes últimos - dada a sua validade racional implicam que os primeiros deles se aproximem progressiva e inevitavelmente ${ }^{24}$.

Por outro lado, se o pensamento utópico assenta numa projecção fantasiosa, a reflexão kantiana acrescenta à força do dever racional, anteriormente referido, o estímulo decisivo da natureza, que conduz a humanidade ao progresso através da dialéctica do conflito, "mesmo contra a sua vontade" 25 .

23 "Nun spricht die moralisch-praktische Vernunft in uns ihr unwiderstehliches Veto aus: Es soll kein Krieg sein; weder der, welcher zwischen mir und dir im Naturzustande, noch zwischen uns als Staaten, [...] denn das ist nicht die Art, wie jedermann sein Recht suchen soll." (Metaphysic der Sitten, Ak., vol. 6, p. 354).

${ }^{24}$ Cf., no mesmo sentido, Rui Bertrand Romão, "Guerra e natureza humana em Kant", in: SANTOS, Leonel Ribeiro dos (Coord.). Kant: Posteridade e Actualidade. Lisboa: CFUL, 2007, p. 415-16: “O projecto kantiano náo nos parece que haja sido deveras concebido como utópico, na medida em que, desde logo, náo se pode afirmar que descreva um mundo irreal e irrealizável, pensado pelo Autor em termos de utopia e construído como ficçáo racional. [...] Da mesma forma, enquanto objecto tâo-pouco a própria paz perpétua deverá ser considerada como fim utópico. Distante, decerto, mas aproximável, desejável e concretizável.”

${ }^{25}$ Cf. "O que subministra esta garantia é nada menos que a grande artista, a Natureza (natura daedala rerum), de cujo curso mecânico transparece com evidência uma finalidade: através da discórdia 
Nesse sentido, o caminho para a paz não é um produto meramente imaginado pelo ser humano (como sucede nas utopias tradicionais), mas sim um percurso efectivamente impulsionado pela natureza, verdadeiro fio condutor da história.

Tal "garantia” [Gewähr] da paz não dispensa, contudo, o vigor da acção humana. Não estamos no campo de uma história pré-determinada, mas antes face a uma visão ambivalente do progresso, misto de uma teleologia natural e da intervenção livre do homem - no que não é mais do que um novo princípio antagónico, neste caso operando a conexão entre a filosofia da história e o pensamento kantiano ${ }^{26}$. De um lado, a natureza assegura as condiçôes gerais de prossecução da paz, mas, por outro, cabe ao homem tomar a iniciativa de criar os mecanismos específicos que afinal a concretizem. Estes não poderão deixar de instituir formas políticas conformes ao direito (quer no nível interno dos Estados, quer nas relaçóes internacionais), embora pouco ou nada saibamos sobre as condiçóes peculiares em que se constituem. Kant preferiu manter-se silencioso nesse campo, sublinhando assim o papel interventivo do homem na história, bem como a possibilidade de a mesma seguir inúmeros destinos diferentes - ainda que na direcção do mesmo "fim último" (a paz).

A última palavra de Kant nesse domínio constitui, por conseguinte, um apelo ao empenho do homem na construçáo da paz, ideia da qual ele progressivamente se aproxima, à medida que a mesma é protegida e cultivada. Não por acaso, a obra seminal kantiana sobre essa matéria intitula-se Zum ewigen Frieden (Para a Paz Perpétua), título teimosamente mal traduzido em várias línguas europeias, ocultando-se o termo alemão "zum" ou substituindo-o

dos homens, fazer surgir a harmonia, mesmo contra a sua vontade." ("Das, was diese Gewähr (Garantie) leistet, ist nichts Geringeres, als die große Künstlerin Natur (natura daedala rerum), aus deren mechanischem Laufe sichtbarlich Zweckmäßigkeit hervorleuchtet, durch die Zwietracht der Menschen Eintracht selbst wider ihren Willen emporkommen zu lassen [...]",(KANT, Immanuel. Zum ewigen Frieden, Ak., vol. 8, p. 360).

${ }^{26}$ Ao defender que a ideia de progresso é ao mesmo tempo determinada pela natureza e criada pelo homem, Kant detém-se sobre um tema clássico da filosofia ocidental (a saber, pensar a complexa relação entre "liberdade" e "necessidade"), o qual perspectiva à luz de um preceito antagónico todavia conciliável no plano prático. Para Kant, o facto de a natureza surgir como o fio condutor da história náo significa que não caiba ao homem um papel determinante na realização da mesma; em grande medida, é justamente porque a primeira o estimula a actuar no sentido da paz perpétua que ele não pode deixar de a procurar (preceito que, aliás, a razão torna compulsório), embora os aspectos específicos e a natureza peculiar de tal procura e (eventual) conquista decorram das acçóes humanas livremente produzidas. Para uma análise desse intrincado tema do argumentário kantiano (que, por motivos de espaço, não podemos tratar em detalhe no nosso artigo), cf. SOROMENHO-MARQUES, Viriato. Razão e Progresso na Filosofia de Kant. Lisboa: Colibri, 1998, p. 239-262; e também KNIPPENBERG, Joseph. "The Politics of Kant's Philosophy". In: Kant \& Political Philosophy. The Contemporary Legacy, New Haven \& London: Yale University Press, 1993, p. 162 e ss. 
por um simples "der" (daí resultando La Paix Perpétuelle, A Paz Perpétua, Perpetual Peace etc.), quando, na verdade, Kant pretendia sublinhar a ideia de um processo, de um caminho para a paz perpétua, e não simplesmente descrever um estádio do progresso que surgiria bruscamente, fruto de um qualquer Deus ex machina. Pois, com efeito - e para desventura da humanidade -, a paz só será possível na sequência de uma laboriosa tarefa, de um gradual e demorado amadurecimento das instituiçóes jurídicas, políticas, culturais e sociais - cuja actual fragilidade revela que há ainda um longo caminho a percorrer...

ANDRÉ, José Gomes. The concept of antagonism in Kant's political philosophy. Trans/ Form/Ação, Marília, v. 35, n. 2, p. 31-50, Maio/Ago., 2012.

\begin{abstract}
Despite its importance in the conceptual architecture of Kantian thought, the notion of antagonism rarely receives special attention from Kant scholars. This paper challenges such disregard, highlighting the relevance of the concept, particularly in the realm of Kant's political philosophy. I will consider specifically the duality/convergence of the concepts of "war" and "peace", and how the notion of antagonism constitutes a solid foundation for the Kantian idea of progress. I wish to show how the proposal to edify a state of right (on the internal and external level) is, after all, produced by a negative stimulus - inter-subjective disagreement and the need for men to understand each other in order to guarantee their own survival. This analysis will bring forth the close connection between a dynamic of conflict and the inevitable development of man's natural disposition toward a state of mutual concord.
\end{abstract}

KEYWORDS: Kant. Political philosophy. Antagonism. War. Peace.

Recebido em: 20.09.2011

Aceito em: 30.01 .2012 